\title{
Scaling the Effectiveness of Existing Techniques towards Enhancing Performance of UWB Antenna
}

\author{
Aijaz Ali Khan \\ Associate. Prof. Dept of E\&CE. \\ HKBK College of Engineering Bangalore, India
}

\author{
Suraiya Tarannum, Ph.D. \\ Professor, Dept. of E\&CE. \\ HKBK College of Engineering Bangalore, India
}

\begin{abstract}
The present era of network and communication system is witnessing an increasing adoption of next generation wireless communication system. In this regards, the Ultra Wideband (UWB) technologies have already played a significant role in many applications pertaining to Wireless personal area (WPAN) network with higher data rates and some of its unique capabilities that are seemed in other variants of WPAN. The main purpose of this paper is to perform a thorough investigation of the existing techniques for enhancing the performance of UWB in order to understand what are the set of problems that are still not addressed by prior studies. The paper also discusses the existing survey works and discusses their level of effectiveness followed by discussion of all the significant literatures related to the topic. Finally, the paper extracts some significant research gaps after studying the existing research contributions.
\end{abstract}

\section{Keywords}

Ultra Wideband, UWB, Wireless Personal Area Network, Antenna Theory.

\section{INTRODUCTION}

With the tremendous growth of the wireless communication in the present era, the technological changes are trying to cater up the dynamic needs of customers. Although the family of IEEE 802.11 standards of its family provides extensible set of standards to enable such communications, but still there is a trade-off of the existing technology and the customer demands [1]. The new generations of the wireless radio communication are anticipated to mitigate the issues of interference, energy efficiency, coverage and connectivity and thereby ensure reliable networking among the resources and clients [2]. The focus of this study is in wireless personal area networking (WPAN) principle called Ultra Wideband (UWB) antenna that are found to be increasingly used in the wireless communication system. UWB is a technology that allows transmission of data packets over a large bandwidth more than $500 \mathrm{MHz}$ frequency with shared spectrum for the users. The standards of UWB are given by Federal Communication Commission (FCC) in United States that intends to formulate standards for allowing maximum data rate in WPAN [3]. UWB differs from traditional wireless network by the inherent ability to transmit data packet over varying levels of power, varying level of frequency using shorter pulses of the signals. The modulation technique is applied on shorter pulse of UWB antenna by performing encoding of the pulse polarity, and amplitude. With the sporadic transmission of shorter pulses less than $60 \mathrm{~cm}$, UWB antenna can support maximum channel capacity as well as can enter into certain areas of infrastructure where Bluetooth fails. The significant advantage of UWB antenna is its capability to predict the duration of transmission at multiple frequencies for mitigating propagation issues in multipath and overlapping of the source signal and the multipath fading. Owing to such potential benefits, UWB antenna is increasingly being used in consumer electronics that ensures higher rate of data transmission, minimal power, minimal cost, accurate localization system with very minimal level of interference. One of the interesting feature of UWB antenna system is its capability to generate noise-like pulses that are highly resilient against traffic jamming as well as multipath fading [4]. The existing radio communication system is therefore not impacted by the UWB transmission owing to lower level of interference. There are various levels of applications for the UWB antenna. It was found that UWB antenna is much appropriate for short-distance application as it is a part of WPAN. Hence, various indoor localization applications adopt UWB technology. The high rate of data is simple to be engineered owing to the shorted period of the small pulse range. It is also possible to exchange the rate of data for certain value closer to pulse energy per data bit using a sophisticated coding techniques. The wireless streaming systems in near distance, transmission of multimedia contents in wireless medium, portable multimedia players have already used UWB technology. Owing to highly accurate tracking capabilities, it is also used in localization system. One of the good examples is wireless communication in healthcare industry and institutional campus of enabling shorter distance communication. However, UWB is also associated with various loopholes and research challenges. This topic is in constant attention since the year 1995. However a research question arises is what are the research issues that have been investigated till date. The answer to this research question will lead the novel researcher to understand the present situation and assist to formulate the new solutions effectively. Hence, paper is present an in-depth review of existing survey papers as well as implementation papers to extract the research gap pertaining to performance enhancement in UWB. Section 2 discusses about the significance of UWB antenna followed by Section 3 that has discussed about the existing survey studies. Section 4 discusses about the existing implementation towards enhancing the performance of UWB antenna followed by brief discussion of research gap in Section 5. Finally, Section 6 makes some concluding remarks.

\section{SIGNIFICANCE OF UWB ANTENNA}

At present, there are various radio-communication based technologies that aim for better and efficient service delivery. Among the various wireless radio-communication technologies [5], Ultra wideband (UWB) system plays a significant role. The theory of UWB antenna is usually studied from viewpoint of linear system, where the characteristics are studied by either time domain or frequency domain. Both the domain of applications uses complete information of the radiation. In terms of bandwidth, the common definition of UWB is mathematically represented as: 
In the above representation (1), $\beta$ max and $\beta$ min are considered as maximum and minimal limits of the bandwidth. The impulse that is fed to the UWB antenna is usually subjected to differentiation, dispersion, radiation, and losses. Referring to Fig.1, the study of UWB antenna is carried out by tracking the performance of spectral efficiency in terms of i) peak value of envelop, ii) envelop width, iii) Ringing, iv) transient gain, v) gain in frequency domain, vi) group delay, vii) mean group delay, and viii) relative group delay [6]. The design of the antenna in UWB is characterized with uniform directionality as well as omni-directionality of the radiating patterns, wide bandwidth impedance, fixed polarization, and maximal efficiency in radiation. Owning to these inherent characteristics, UWB is plays a major role in advance communication technologies like wireless sensor networks with better assurity of minimal cost and complexity. UWB is also known for its prioritizing the impedance transformation. At present, there are various types of UWB antenna viz. directional and non-directional UWB antenna. It is also classified as electric (e.g. dipoles and Hornes) and magnetic antennas (loops and stats). Some of the design principles of UWB that are increasingly used in existing research studies are as follows:

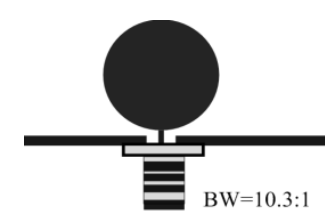

(a) circular

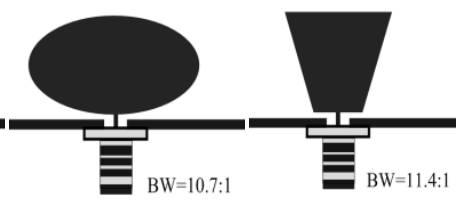

(b) elliptical

(c) trapezoidal

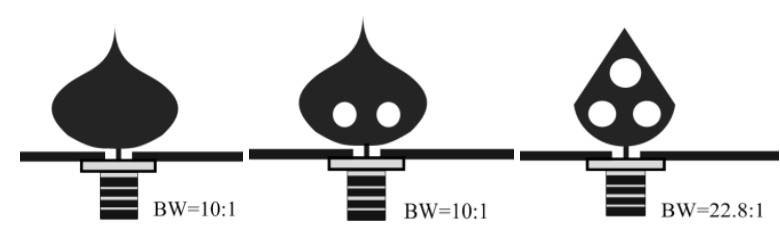

(d) PICA

(e) PICA with two holes

(f) leaf-shaped

\section{Figure 1 Existing Designs of UWB Antenna}

The principle of antenna theory says that UWB follows peculiar traits of bandwidth radiation that is based on i) frequency independent antennas, travelling wave structure, self complementary antenna, and electrical small antennas [7]. There are various potential characteristics of the UWB antenna, which makes the technology worthy to get adopted in futuristic applications. Some of them are as follows:

\subsection{Maximal Transmission capability}

UWB supports data rate transmission more than $500 \mathrm{mbps}$ in the transmission range of 10 meters. Hence, such potential and robust antenna design can be applied on maximum number of application, where heavier files are required to be transmitted e.g. multimedia file transmission or medical image transmission.

\subsection{Reduced Loss Penetration}

There may be certain cases of wireless personal area network, which can't be emitted inside building or certain areas with obstruction. But UWB antenna has the capability to work in such complex obstructive environment under both line and non-line of sights. Applications like indoor localization are one good example of this characteristic.

\subsection{Maximal Range of Precision}

UWB uses short pulse signal for which reason it takes a fraction of sections to generate and transmit it. Therefore, UWB antenna have maximal resolution in time domain and can furnish higher range of accuracy in terms of application for enabling various tracking of the objects in complex environment.

\subsection{Maximal Security}

UWB antenna is known for lower scale of power spectral density. As UWB antenna generates shorter pulse and they function in less extents of noise, so it is almost impossible for the attacker to understand the type of the signal and intercept it. Moreover, owing to lower bandwidth of UWB antenna, rate of interference is very low.

\subsection{Resiliency toward channel fading}

The probability of channel fading on multiple paths is very less in UWB antennal in both sparse and dense environment of nodes. Owing to this characteristics, the complexity of both transmitter as well as receiver is very less in UWB.

\subsection{Cost-Effective Devices}

The hardware of UWB antenna e.g. baseband and RF chip, CMOS, converters etc are very much low cost for which purpose the technical adoption goes high. The hardware circuit designs are low-powered and are independent of any oscillators and mixers.

\subsection{Supportability of Reconfigurable Networks}

Owing to above mentioned potential characteristics of UWB antenna, various reconfigurable networks like OFDM, Optical network, Global Positioning System, Wireless LAN, wireless sensor network, Mobile Adhoc Network etc.

Although UWB antenna has potential advantages, they suffer from certain limitations too. UWB functions on pulse operation which is usually IEEE 802.15.4a. However, adoption of impulse response significantly influences strength of receiver signal, rate of data communication, and radar resolution. It was also found that antennas that consider passing resonances of spurious surface currents negatively affect the performance of UWB antenna in applications. Various applications and advantage, disadvantage of UWB is highlighted in Table 1.

Table 1 Summary of Effectiveness of UWB charecteristics

\begin{tabular}{|l|l|l|l|}
\hline \multicolumn{1}{|c|}{ UWB Property } & \multicolumn{1}{|c|}{ Advantages } & \multicolumn{1}{c|}{ Disadvantages } & \multicolumn{1}{c|}{ Applications } \\
\hline $\begin{array}{l}\text { Very wide fractional and } \\
\text { absolute RF bandwidth }\end{array}$ & -High rate communication & $\begin{array}{l}\text {-Potential interference to } \\
\text { existing systems } \\
\text {-Potential for processing gain } \\
\text {-Potential interference from } \\
\text { existing system }\end{array}$ & $\begin{array}{l}\text {-High-rate WPAN } \\
\text {-Low Power, stealthy } \\
\text { communication }\end{array}$ \\
& & & $\begin{array}{l}\text {-Indoor localization } \\
\text {-Multiple access }\end{array}$ \\
\hline
\end{tabular}




\begin{tabular}{|l|l|l|l|}
\hline Very Short Pulse & $\begin{array}{l}\text {-Direct resolvability of discrete } \\
\text { multipath components } \\
\text {-Diversity gain }\end{array}$ & $\begin{array}{l}\text {-large number of multipath } \\
\text {-Long synchronization times }\end{array}$ & $\begin{array}{l}\text {-Low-Power communication } \\
\text { and localization }\end{array}$ \\
\hline $\begin{array}{l}\text { Persistence of multipath } \\
\text { reflectors }\end{array}$ & $\begin{array}{l}\text {-Low fade margins } \\
\text {-Low Power }\end{array}$ & -Scatter in angle of arrival & $\begin{array}{l}\text {-NLOS communication indoors } \\
\text { and on ships }\end{array}$ \\
\hline Camera less transmission & $\begin{array}{l}\text {-Hardware simplicity } \\
\text {-Small hardware }\end{array}$ & $\begin{array}{l}\text { Inapplicability of super- } \\
\text { resolution beam-forming }\end{array}$ & Smart Sensor Networks \\
\hline
\end{tabular}

\section{EXISTING STUDY}

There have been various studies toward Ultra wideband antenna in the past decade. Owing to the potential advantageous features of Ultra wideband antenna, there are various authors who have investigated about its technical efficiency. As the proposed paper mainly targets to understand the effectiveness of the prior literatures and extract the research gap, it is very critical to understand even the existing survey papers. Hence, according to our findings on 2nd Feb, 2015, there are total of 87 survey papers published from 2003 to till date. The primary target to investigate the existing survey paper is to check if there are any authors who have discussed about the most effective work done in past for enhancing the performance of UWB antenna.. It was seen that majority of the existing survey paper are like replica copy of each other. The existing survey papers are more inclined towards theoretical discussion of UWB antenna recursively. Major theoretical discussion includes historical evolution of UWN antenna, design and configuration aspects of UWB antenna, types of UWB antenna (fractal, tapered, biconical, slot etc.). The initial survey paper on this topic was introduced by Schantz [8] in 2003. However, the paper has only discussed theoretical description of the domain with respect to historical advancement of Ultra wideband antenna while there was no discussion of potential research contribution. No significant survey papers were seen much till the year 2006 related to this topic. In the year 2007, Gupta and Mohapatra [9] have discussed the various schemes of ultra wideband especially the MAC aspect of it. However, it has discussed MAC theories, less discussion on performance effectiveness or prior studies. In 2010, a survey on prior and existing system on ultra wideband was discussed by Lim et al. [10]. The focus of the study was mainly on i) Printed circuit board design of UWB antenna and ii) discussion of case studies in this regards. However, the survey work mainly discusses theory of domain and there was no discussion of prior research work and its effectiveness. Elaborated discussion of case study was surveyed by Mok et al. [11] in same year along with its feasibility analysis on ultra wideband. In 2012, Raheel et al. [12] has published a survey paper mainly focusing on discussion of feeding techniques. Study [11], [12] suffers from the problem that it has absolutely not discussed the technical implementation of prior research papers and its effectiveness.

In the same year, Khan et al. [13] have reviewed implementation of 10 research papers focusing on techniques to enhance the performance of ultra wideband. However, number of paper investigated was very less. In 2013, Pondhivya and Rajan [14] have published a survey paper mainly emphasizing on detection schemes for antenna. The survey work has less extent of discussion of prior studies and no attempt to explore research gap or trade off. In 2013, Pulickal et al. [15] have published a survey paper on ultra wideband and its reconfigurable nature with existing cognitive radio system. This survey work has only theoretical discussion and no discussion of prior research work and its effectiveness. In same year, Shinde and Labade [16] have reviewed ultra wideband and Bluetooth specifically. The review paper is extremely less informative contents in 3 pages manuscript s. Patel and Kulkarni [17], in 2014, have presented a survey work on same topic that majorly discusses theory and application of ultra wideband antenna.

Compared to all the discussed survey paper till date, the unique survey work was witnessed in the survey paper of Ali et al. [18] in 2013. The survey work has focused on Frequency modulated UWB receiver and transmitter and have good discussion on performance comparison, however, the study focused only on transceiver. Alim et al. [19] have surveyed the techniques of channel modelling for wireless body area network with theoretical discussion. Kalambe et al. [20] have reviewed frequently used Microstrip antenna with less focus on significance to extract tradeoff in existing study.

\section{EXISTING TECHNIQUES}

The design principle of antenna plays a critical role in the application of UWB system, which works in completely different way than narrowband systems. All the existing implementations towards UWB research are focused on incorporating much narrow pulse of signal for accomplishing higher extents of the bandwidth standards. The existing studies have also focused on the fabrication as well as the design aspects of UWB antenna that was found to be associated with higher level of computational complexities. After investigating the existing system, it was found that UWB antenna is closely associated with the design issues owing to larger extent of fractional channel capacity. Certain studies [21] have also discussed that UWB antenna must encapsulate the multiple octave channel capacity for the purpose of transmitting signals in the sequence of nanoseconds time period. Certain studies also emphasized on the minimal distortions of the pulse for retaining the conventional shape of the signals being generated by the UWB antenna. However, majority of the studies [22], [23], [24] have focused on impulse responses of UWB antenna owning to the capability of changing the shape of the short pulses of UWB signals. The authors in these studies e.g. [25] have emphasized on restricting the delay and amplitude for the distortions that should be minimum to specific threshold factor for ensuring better performance of UWB antenna.

Such issues were found to be addressed using Microstrip antenna by certain authors [26]. Numerous solutions towards bandwidth optimization were also seen in the literatures [27] considering various shapes of the pulse that can accommodate multiple signals. Such studies find better compatibility with the reconfigurable networks e.g. OFDM. Some of the notable studies found are that of [28][29][30]. The authors in [31] have introduced triangular monopole, while authors in [32] and [33] have considered circular and elliptical monopoles 
design. Studies e.g. [34] and [35] have focused on ring and circular disk shape of UWB antenna. Adoption of triple-feed configuration was seen $n$ the work of [36], where the author have used planer square monopole antenna. Such techniques were seen to excite more persistent current on monopole antenna. The advantage of such technique is no overlapping with the surface current on multiple mode of resonance, when feeding structure is implicated on elliptical or circular monopole UWB antenna. Studied performed by author in [37] have focused on polarization techniques using Microstrip antenna. Implementation towards bandwidth efficiency was also investigated by various authors. The work done by author in [38] has discussed a technique that used thicker substrate without adding any cross polarization and without any dependency of thick probe. The authors have used hardware based approach to enhance the performance of UWB antenna. Various implementation works e.g. [39][40][41] have focused on unique techniques of patch shape, tapered association between the feed and patch line, enhanced ground plane, and usage of slots that require fractal shapes knowledge. The authors have used these techniques to attain better performance in impedance over the variable ranges of UBL signals.

Although the study have considered various technique to accomplish better bandwidth, but various extrinsic features like channel model, channel state, interference, and design principle of antenna was the major research challenge, which was not found much to be addressed. Certain studies [42] that have adopted planer monopole antenna are found to be frequently adopted by other studies too [43], [44]. However, the prime trade-off observed in such studies are that all these studies are found to have major degradation of pattern in radiation confirmed from radiation analysis, when observed from higher level of frequencies. It is imperative that such issues cause failures of various critical applications e.g. cognitive radio, which has strong dependency of persistent omni-directional pattern of radiation. These issues were addressed in [45], where the authors have introduced circular ground shaped UWB antenna. Authors in [46] have used notched ground shaped antenna to enhance the impedance performance of UWB antenna. Hence, every study is accompanied by certain trade-off that remains unaddressed. Roblin et al. [47] have focused on signal distortion problems in solving the issues of antenna and have adopted a timedomain techniques using energy, scattering as performance parameters. The outcomes of the study were not found benchmarked. Adoption of numerical analysis for Ultra Wideband Antenna was carried out by Li et al. [48] using three-dimensional time domain. The outcome of the study have been evaluated using voltage standing wave ratio, source and receiver voltage and found to be offering high fidelity in the transmission. A novelty in the antenna design was seen in the study of Zehforoosh et al. [49] who have emphasized on bandwidth within the ultra waves and have used the technique of stacked multi-resonator patches. The outcomes of the study were evaluated using bandwidth, antenna size, efficiency, gain, and return loss. The outcomes were not benchmarked and found to posses maximized gain and bandwidth consumption. Investigation towards Microstrip ultra wideband antenna was seen in the study of Lim et al. [50] focusing on compact design and construction. The authors have used numerical techniques and outcomes were evaluated suing power spectral density, return loss, group delay, gain, and efficiency. The outcomes show higher potential interference between ultra wideband and wireless LAN. Ghassemi et al. [51] have presented a design of Microstrip antenna where the authors have focused on problems pertaining to multiple lengths and excited by $\mathrm{U}$ shaped feed line using double slots. The study have adopted method of moments and evaluated using bandwidth and gain. The study suffers from critical need of optimization principle for radiation pattern. Cai et al. [52] have investigated on frequency dependency of ultra wideband antenna for emphasizing the issues of edge effect of antenna. The outcomes were evaluated using received power and surface current mainly. The outcomes suffer from maximized cross section of antenna. Study towards compact Microstrip antenna was carried out by Kasi et al. [53] where the authors have focused on problems relating to ultra wideband patch antenna with rectangular slot and narrow impedance bandwidth. The outcome of the study was found to have higher cost and complexity issues as evaluated using return loss, impedance bandwidth etc. Kliros et al. [54] have investigated on the problems of three-dimensional conical antennas that are quite bulky and troublesome to fabricate and re-configure. The author have used numerical techniques of finite difference time domain and the outcomes were recorded with maximum radial distance, maximum reflection coefficient. Focusing on enhancing the channel capacity, Gouda and Yousef [55] have addressed the problem to design a UWB antenna in a narrow band. The authors have adopted the technique of UWB planar printed circuit board (PCB) antenna design and carried out the analysis using Return loss and Radiation pattern mainly. The outcomes suffer from high complexity with respect to cost and compactness. Thorat et al. [56] have presented a technique to enhance operating bandwidth, structural shape, without affecting the size of an antenna. The authors have used AnSoft- HFSS v.11 software and simulation of modified rectangular Microstrip patch antenna. The outcome accomplished infers that lingering of current or wave must have improved. Xiong et al. [57] have focused on addressing the issues of Impedance Bandwidth and Gain Improvement in Microstrip antenna. The authors have used Planar-patterned meta-material concepts using Ansoft HFSS considering the performance parameters of reflection coefficient, return loss, and peak gain. The outcome of the study shows improves Gain, reduce the size of antenna. A comparative study has been performed by Ghuge et al. [58] towards improving the gain factor on Microstrip patch antenna. In the study, the authors infers that existing system suffers from a number of serious drawbacks, including very narrow bandwidth, high feed network losses, poor cross polarization, and low power handling capacity. Ramos and Rego [59] have adopted numerical techniques for modelling the radiation patterns of antenna particularly focusing on printed antenna analysis for a high degree of discretization. The outcome of the study was evaluated by gain and radiation patterns and shows that there is a need to improve narrowband antennas, accuracy and efficiency. Focusing on the issues of enhanced bandwidth, Rao et al. [60] have adopted H-U-E slotted antenna using Ansoft's HFSS software. The outcomes were evaluated using impedance BW, return loss, radiation pattern and found to have a need compact, low profile, and wideband antennas.

\section{RESEACH GAP}

After reviewing the existing studies discussed in prior section, following are the brief discussion of the research gaps:

\subsection{Few Studies towards Soft Computational Approach}

It has been observed that majority of the studies till dates are accomplished using hardware based approach (PCB based design approach). Although, working on hardware based 
approach give some true figures of the outcomes, but it is also associated with various uncertainties, when the experimental or laboratory test-bed is altered. A software computation approach with robust mathematical modelling enables the researcher to study the maximum scope of their designed prototype and give the chance to understand the workability in multiple challenging environments.

\subsection{Few benchmarked Studies}

All the existing techniques are found to witness few benchmarking. Until and unless the outcomes accomplished by the authors are not found to be compared with existing standards or existing implementation studies, it is hard to come to conclusion about the effectiveness of those particular studies. The outcomes are studied with altered simulation parameters by the authors and not seem much to make comparative performance analysis.

\subsection{Vagueness in existing implementations}

Some of the studies are found to be quite contradicting in the existing system, where it was found to say that UWB differs from narrowband technique and the studies infers that it is not possible to integrate them [61]. Whereas it can be said that it is highly possible to use narrowband technique for the purpose of enhancing the UWB antenna. Such implications can also address the existing obstructive factor of power limitation of the UWB.

\subsection{Less work towards modulation scheme}

Modulation scheme plays a crucial role in enhancing the performance of UWB antenna. The existing system doesn't find any significant studies that have introduced novelty in the modulation scheme for the purpose of enhancing the system performance of UWB antenna. A simpler technique is therefore required for this purpose.

\subsection{Applicability}

The hardware based studies in existing system gives lesser extent of applicability. The existing analytical approach studies doesn't discusses about explicit applicability. All the studies that discusses about enhancing the performance of UWB antenna have never discussed or experimented with a particular application to prove the efficiency level. It is critical as UWB in wireless sensor network works in completely different way as compared to mobile adhoc network or WLAN. Hence, every applications of networking have different topological as well as routing protocols with unique and heterogeneous technical issues. Although, it is not possible to work on all the networking applications, but there should be some starting point. The most existing technological hype of Internet-of-Things, reconfigurable networks, cloud computing, inter-domain routing protocol in heterogeneous mobile adhoc network makes such wireless communication of UWB more complicated. And hence if UWB is studied with respect to some networking applications like WSN and then studied for performance enhancement, it will be a real good contribution in the research community. However, till date, no such attempts have been observed.

\section{CONCLUSION}

UWB antenna has already played a significant role in the field of wireless personal area networking and advanced antenna theory owing to its potential advantages. However, it is accompanied by certain loopholes too. This paper has initially discussed about the theoretical implications of UWB antenna with compact description of fundamental charecteristics and problems associated with it. The paper has also reviewed some of the existing survey paper in order to showcase the unique contribution of the proposed survey work. Finally, the manuscript has reviewed all the significant studies introduced in the last decade for enhancing the performance of UWB antenna. The existing techniques are studied in-depth with respect to problems focused and performance study. Finally, the paper discusses about the research gap from the existing studies. Our future work will be in a direction to overcome the research gap extracted from this review work and come up with more efficient schema to address the issues in UWB antenna.

\section{REFERENCES}

[1] Jakobs, K.2009.Information Communication Technology Standardization for E-Business Sectors: Integrating Supply and Demand Factors. Information Science References

[2] Bidgoli, H.2006. Handbook of Information Security, Information Warfare, Social, Legal, and Security Faundations.John Wiley \& Sons

[3] oppermann, I., Hämäläinen, M., Iinatti, J.2004. UWB: Theory and Applications. John Wiley \& Sons

[4] "FCC Record: A Comprehensive Compilation of Decisions, Reports, Public Notices, and Other Documents of the Federal Communications Commission of the United States", United States. Federal Communications Commission, 2003

[5] Zhuang, W., Shen, X.S., and Bi, Q.2003. Ultra- wideband wireless communications. Wireless Communications and Mobile Computing, Vol. 3, No. 6, pp. 663-685

[6] Wiesbeck, W., Adamiuk, G., and Sturm, C.2009. Basic properties and design principles of UWB antennas. Proceedings of the IEEE, Vol. 97, No. 2, pp. 372-385

[7] Wang, J.H.2000. The spiral as a traveling wave structure for broadband antenna applications. Electromagnetic, Vol. 20, No. 4, pp.323-342

[8] Schantz, H.G.2004. A brief history of UWB antennas. IEEE Aerospace and Electronic Systems Magazine, Vol. 19, No. 4, pp.22-26

[9] Gupta, A., and Mohapatra, P.2007. A survey on ultra wide band medium access control schemes. Computer Networks, Vol. 51, No. 11, pp.2976-2993

[10] Lim, E.G., Wang, Z., Lei, C-U., Wang, Y., and Man, K.L.2010. Ultra Wideband Antennas-Past and Present IAENG International journal of computer science, Vol. 37, No. 3, pp.304-314

[11] Mok, E., Xia, L., Retscher, G., and Tian, H.2010. A case study on the feasibility and performance of an UWBAoA real time location system for resources management of civil construction projects. Journal of Applied Geodesy, Vol. 4, No. 1, pp.23-32

[12] Rahel, K., Bashir, S., and Fazal, N.2012. Review of techniques for designing printed antennas for UWB application. International Journal of Sciences \& Emerging Technologies, Vol.1, No. 2, pp. 48-60

[13] Khan, A.R., Gulhane, S.M., Kaushik, P.G.2014. Ultra Wide Band Communication in Underground Mine channel : A Related Review. International Journal of Advancements in Technology, Vol. 3, No. 4 
[14] Pondhivya, J.P.J., Pradheep, B., Rajan, T.2013. A Profound Survey on Various Detection Schemes for Ultra Wideband Systems. International Journal of Advanced Research in Electronics and Communication Engineering (IJARECE), Vol.2, Issue.4

[15] Pulickal, N., Prakash, A.K., Kumar, D. S.2013. A Survey on UWB and Reconfigurable Antennas for Cognitive Radio Application. International Journal of Advanced Research in Electrical, Electronics and Instrumentation Engineering, Vol. 2, Iss.12

[16] Shinde, S., Labade, R.P.2013. A Review on Integrated Bluetooth Ultra Wide Band Patch Antenna. International Journal of Scientific \& Engineering Research, Vol. 4, Issue. 5

[17] Patel, K. R., Kulkarni, R.2014. Ultra-Wideband (UWB) Wireless systems - A Survey. VESIT, International Technological Conference

[18] Ali, M., and Shawkey, H., Zekry, A.2013. A Survey on FM-UWB Transceivers. International Journal of Computer Applications, Vol. 61, No.6

[19] Alim, A., and Hossain, M.2014. A Study and Analysis of Channel Modeling for the Ultra Wide Band Wireless Body Area Network. Journal of Convergence Information Technology, Vol. 01, Issue. 01

[20] Kalambe, N., Thakur, D., Paul, S.2015. Review of Microstrip Patch Antenna Using UWB for Wireless Communication Devices. International Journal of Computer Science and Mobile Computing, Vol.4 Issue.1, pp. 128-133

[21] Yazdandoost, Y.K., and Kohno, R.2005. Design and analysis of an antenna for ultra-wideband system. In 14th IST Mobile and Wireless Communications Summit

[22] Chiu,S., Chuang, J., and D.G.Michelson,.2010. Characterization of UWB channel impulse responses within the passenger cabin of a boeing 737-200 aircraft. Antennas and Propagation, IEEE Transactions, Vol.58, No. 3, pp. 935-945

[23] Dezfooliyan, A., and Weiner, A.M.2012. Experimental investigation of UWB impulse response and time reversal technique up to $12 \mathrm{GHz}$ : unidirectional and directional antennas. Antennas and Propagation, IEEE Transactions, Vol.60, No. 7, pp. 3407-3415

[24] Molisch, A.F.2009. Ultra-wide-band propagation channels. Proceedings of the IEEE, Vol. 97, No. 2, pp. 353-371

[25] Guo, L.2009. Study and miniaturization of antennas for ultra wideband communication systems. PhD diss

[26] Singh, I., and Tripathi, V.S.2011. Micro strip Patch Antenna and its Applications: a Survey. Int. J. Comp. Tech. Appl, Vol. 2, No. 5, pp. 1595-1599

[27] Dumoulin, A., John, M., Ammann, M.J., and McEvoy, P.2012. Optimized monopole and dipole antennas for UWB asset tag location systems. Antennas and Propagation, IEEE Transactions, Vol.60, No. 6, pp. 2896-2904

[28] Dutta, A.2008. Reconfigurable OFDM Receiver for Next Generation Wireless Mesh. ProQuest
[29] Zhang, Q., Kokkeler, A.B.J., and Smit, G.J.M.2007. An efficient FFT for OFDM based cognitive radio on a reconfigurable architecture. In Communications, ICC'07. IEEE International Conference, pp. 6522-6526

[30] Nolan, K.E., Doyle, L., Mackenziey, P., and Mahony, D.O.2005. Interference avoidance dynamic adaptive OFDM using a reconfigurable radio platform. In the 7th IFIP International Conference on Mobile and Wireless Communications Networks

[31] Wang, L., Wu, W., Shi, X.-W., Wei, F., and Huang, Q.L.2008. Design of a novel monopole UWB antenna with a notched ground. Progress In Electromagnetic Research C, Vol. 5, pp. 13-20

[32] Sayidmarie, K. H., and Fadhel, Y. A.2011. Selfcomplementary circular disk antenna for UWB applications. Progress In Electromagnetic Research C, Vol. 24, pp. 111-122

[33] Kulkarni, M.K., and Kasabegoudar, V.G.2013. A CPWfed triangular monopole antenna with staircase ground for UWB applications. Int. J. Wireless Communications and Mobile Computing, Vol. 1, No. 4, pp.129-135

[34] Kshetrimayum, R.Singh, and R.Pillalamarri.2009.UWB printed monopole antenna with a notch frequency for coexistence with IEEE 802.1 a WLAN devices.In Proc. 5th National Conference on Communications (NCC)

[35] Fadhel, Y.A., and Sayidmarie, K.H.2012. A Novel UWB Impedance Matching for Planar Circular Monopole Antenna via Meandering the Microstrip Feed Line. Antennas and Propagation Conference (LAPC), Loughborough

[36] Sayidmarie, K.H., and Fadhel, Y.A.2012. Design aspects of UWB printed elliptical monopole antenna with impedance matching.In Antennas and Propagation Conference (LAPC), Loughborough, pp. 1-4

[37] Shakeeb, M.2010. "Circularly Polarized Microstrip Antenna. PhD diss., Concordia University Montreal, Quebec, Canada

[38] Zhu, F., Ho, A., A-Alhameed, R. A., See, C. H., Brown, T., Li, J., Wei, G., and Xu, J.2014. Ultra-wideband dualpolarized patch antenna with four capacitive coupled feeds

[39] Safatly, L., Bkassiny, M., Al-Husseini, M., and El-Haij, A.2014. Cognitive Radio Transceivers: RF, Spectrum Sensing, and Learning Algorithms Review. International Journal of Antennas and Propagation

[40] Liang, X. L.2012. Ultra-Wideband Antenna and Design, Inech,

[41] Karlsson, M.2008. Ultra-wideband Antenna and Radio Front-end Systems.

[42] Alhefnawy, M.Y., Assisi, A., Almotaafy, H., Safwat, A., and Youssef, M. I.2009. Design and implementation of a novel planer UWB monopole antenna for multipath environments. In 13th International Conference on Aerospace Sciences \& Aviation Technology

[43] Chauhan, S., and Singhal, P.K.2014. Design of UWB Monopole Antenna with EBG Structure and Ground with Rectangular Slots. International Journal of Emerging Trends in Science and Technology, Vol. 1, No. 04 
[44] Kaur, A.2012. Electronically Steerable planer Phased Array Antenna. International Journal of Engineering Trends and Technologie, Vol. 3,No. 6, pp. 708-709

[45] Molisch, A.F., Greenstein, L.J., and Shafi, M.2009. Propagation issues for cognitive radio. Proceedings of the IEEE, Vol.97, No. 5, pp. 787-804

[46] Lee, W-S.,.Kim, K.J., Kim, D-Z., and Yu J-W.2005. Compact frequency- notched wideband planar monopole antenna with an L- shape ground plane. Microwave and optical technology letters, Vol. 46, No. 4, pp.340-343

[47] Roblin, C., Bories, S., and Sibille, A.2003. Characterization tools of antennas in the time domain. In Int. Workshop on Ultra Wideband Systems IWUBS, pp. $2-5$

[48] Li, X.,Hagness, S.C., Choi, M.K., and Weide, D.W.V.D.2003.Numerical and experimental investigation of an ultrawideband ridged pyramidal horn antenna with curved launching plane for pulse radiation. Antennas and Wireless Propagation Letters, IEEE, Vol. 2, No. 1 , pp. 259-262

[49] Zehforoosh, Y., Ghobadi, C., and Nourinia, J.2006. Antenna design for ultra wideband application using a new multilayer structure. PIER Online, Vol. 2, No. 6, pp. 544-549

[50] Lim, K-S., Nagalingam, M., and Tan, C-P. 2008. Design and construction of microstrip UWB antenna with time domain analysis. Progress In Electromagnetics Research, Vol. 3, pp. 153-164

[51] Ghassemi, N.J., Mohassel, R., and Neshati, M.H.2008. Microstrip antenna design for ultra wideband application by using two slots. Session 1AP, Vol. 61

[52] Cai, Y., Cui, H., Feng, Z., and Xiang, D. 2010. The research of the frequency dependency of UWB antenna radiation pattern. In IEEE International Conference on Ultra-Wideband, Vol. 2, pp. 1-4

[53] Kasi, B., Ping, L.C., and. Chakrabarty, C.K.2011. A compact microstrip antenna for ultra wideband applications. European Journal of Scientific Research, Vol. 67, No. 1, pp. 45-51

[54] Kliros, G.S.2011. Simulated Performance of Conical Antennas Using Matlab-Based Finite-Difference Time Domain (FDTD) Code. INTECH Open Access Publisher

[55] Gouda, M., Yousef, M.Y.M.2012.Bandwidth Enhancement Techniques Comparison for Ultra Wideband Microstrip Antennas for Wireless Application. Journal of Theoretical and Applied Information Technology, Vol. 35, No.2

[56] Thorat, S., Jaiswal, R. C., Rajkumar, and Lokhande, S.D. 2012. Efficient techniques for bandwidth improvement of microstrip patch antenna. International Journal of Computer Networks and Wireless Communications (IJCNWC), pp.2728-732

[57] Xiong, H., Hong, J-S., and Peng, Y-H.2012. Impedance bandwidth and gain improvement for micro strip antenna using met materials. Radio engineering, Vol. 21, No. 4

[58] Ghuge, M., Khedkar, A. P., and Indulkar, P.U.2014. A Comparative Study of Gain Enhancement Techniques for Microstrip Patch Antenna. International Journal of Engineering Science and Innovative Technology (IJESIT), Vol. 3, Iss.1

[59] Ramos, G.L., and Rego, C.G.2014. Characterization of the radiation pattern of antennas via FDTD and timedomain moment expansion. Journal of Microwaves, Optoelectronics and Electromagnetic Applications. Vol 13, No. 1, pp. 67-84

[60] Chirala, A.P.2014. HUE Shaped Slotted Micro strip Antenna for Bandwidth Enhancement. International Journal of Future Generation Communication and Networking, Vol.7, No.4, pp.141-148

[61] Saeed, R., Khatun, S., Ali, B., and Abdullah, M.2009. Performance enhancement of UWB power control using ranging and narrowband interference mitigation technique.Int Arab J Inf Technol, Vol. 6, No. 2, pp.169178 